\title{
Empirical Research of Portfolio Selection under M-SAD Model Peng Zhang ${ }^{1, a}$,Jingyi Zhou ${ }^{2, b}$ \\ ${ }^{1,2}$ School of Management, Wuhan University of Science and Technology, Wuhan, P.R.China, 430081. \\ azhangpeng300478@yahoo.com.cn, 'bny_2011@126.com
}

Key words: $\quad$ portfolio selection; M-SAD; risk elastic; short sale

\begin{abstract}
The mean semi-absolute deviation is the extension and development from the mean-variance theory which proposed by Markowitz. This paper studied the Mean-SAD (semi-variance deviation) model without the short selling and used the Chinese securities market's 20 stocks to test the efficient of the model. We got the conclusion that M-SAD model can effectively direct the decision in portfolio selection. Based on the result of the empirical research, the paper prospects the application of M-SAD model in our country.
\end{abstract}

\section{Introduction}

Portfolio theory deals with the question of how to find an optimal distribution of the wealth among various assets. Humans have always looked for ways to enhance one's regular incomes through good investing [1]. The works by Markowitz (1952) suggests minimizing variance and maximizing mean of portfolio, simultaneously, to get the best portfolio selection[3]. In 1959, Markowitz elucidate on risk quantification for portfolio selection and recommends using semi-variance instead of variance[5]. With expected absolute deviation to describe risk, Konno and Yamazaki (1991) [6] established a "mean absolute deviation model", advocated to yield absolute deviation and variance as a risk measurement tool, the Markowitz mean absolute deviation, variance as the risk measure is not reasonable. [7]. Recently, Inuiguchi and Ramik(2000)[2] have studied portfolio selection models based on possibility theory. It is always assumed that the distribution functions of possibility returns are known in these portfolio selection models.Kaplan and Alldredge (1997) [4] and Huang (2008) [8]research the properties and computation problem of semi-variance. The main purpose of this thesis is introducing M-SAD model, and testing the applicability and limitations of the investment model of M-SAD in Chinese securities market.

\section{The definition and mathematical description of M-SAD}

Supposing there are $\mathrm{n}$ pieces of securities can be used to invest ,the return rates are $R_{1}, R_{2}, \cdots$, $R_{n}$. that is mean $E\left(R_{i}\right)=r_{i}$, the covariance matrix of the securities, $H=\left(\sigma_{i j}\right)_{n \times n}$, then $\sigma_{i j}=\operatorname{COV}\left(R_{i,} R_{j}\right)$ the proportion for investing the security numbered $i, i=1, \cdots, n$, then $X=\left(x_{1}, x_{2}, \cdots, x_{n}\right)^{T}$,Hence, the return of portfolio is $R_{e}=R_{1} x_{1}+R_{2} x_{2}+\ldots+R_{n} r_{n}$ [3]

Mean

$$
\mathrm{E}\left(R_{e}\right)=r_{e}=r_{1} x_{1}+r_{2} x_{2}+\ldots+r_{n} x_{n}=\sum_{i=1}^{n} r_{i} x_{i}
$$

By introducing the concept of time, Let $r_{i t}$ be the rate of return about the stage numbered $t$ and risk asset numbered $i$, Then mean of invest return rates and expect return rates of the stage numbered $\mathrm{t}$.

The mean of portfolio is

$$
r_{p}=\frac{1}{T} \sum_{i=1}^{n} \sum_{t=1}^{T} r_{t i} x_{i}
$$

Semi-absolute-variance is a way to measure the risk, which is actual invest rates of portfolio less than absolute value of average invest rates of portfolio selection: 


$$
w(x)=\mathrm{E}\left[\left|\left(\sum_{i=1}^{n} R_{i} x_{i}-\mathrm{E}\left|\sum_{i=1}^{n} R_{i} x_{i}\right|\right)\right|\right]
$$

Where

$$
\left(\sum_{i=1}^{n} R_{i} x_{i}-\mathrm{E}\left|\sum_{i=1}^{n} R_{i} x_{i}\right|\right)_{-}=\min \left\{0, \quad \sum_{i=1}^{n}\left(R_{i}-\mathrm{E}\left(R_{i}\right)\right) x_{i}\right\}
$$

Semi-variance Absolute deviation of the expected return rates and invested rates of old stages numbered $t$ can be expressed as[9]:

$$
w_{t}(x)=\left|\min \left\{0, \quad \sum_{i=1}^{n}\left(r_{i t}-r_{i}\right) x_{i}\right\}\right|=\frac{\left|\sum_{i=1}^{n}\left(r_{i t}-r_{i}\right) x_{i}\right|-\sum_{i=1}^{n}\left(r_{i t}-r_{i}\right) x_{i}}{2}
$$

Semi-variance-Absolute Deviation is

$$
w(x)=\frac{1}{T} \sum_{t=1}^{T} w_{t}(x)=\frac{1}{T} \sum_{t=1}^{T} \frac{\left|\sum_{i=1}^{n}\left(r_{i t}-r_{i}\right) x_{i}\right|-\sum_{i=1}^{n}\left(r_{i t}-r_{i}\right) x_{i}}{2}
$$

Without short selling being allowed, the M-SAD portfolio model only contained risk assets is [13]:

$$
\begin{gathered}
\min \frac{1}{T} \sum_{t=1}^{T} \frac{\left|\sum_{i=1}^{n}\left(r_{i t}-r_{i}\right) x_{i}\right|-\sum_{i=1}^{n}\left(r_{i t}-r_{i}\right) x_{i}}{2} \\
\left\{\begin{array}{c}
\sum_{i=1}^{n} r_{i} x_{i} \geq r_{\varepsilon} \\
x_{1}+x_{2}+\ldots+x_{n}=1 \\
x_{1}, x_{2}, \ldots, x_{n} \geq 0
\end{array}\right.
\end{gathered}
$$

Including, $r_{e}$ is the expected return rates, $\min \left(\mathrm{x}_{1}, \mathrm{x}_{2}, \ldots, \mathrm{x}_{\mathrm{n}}\right) \leq r_{e} \leq \max \left(\mathrm{x}_{1}, \mathrm{x}_{2}, \ldots, \mathrm{x}_{\mathrm{n}}\right)$.

This is an empirical research of M-SAD portfolio model. If it had known the price of $\mathrm{n}$ different securities in different $t$ period, $r_{i t}$ is the return rate of security numbered $i$ at the stage numbered $t$. There are many ways to decide the returned rate of security.

Risk elasticity, it means, which from M-V model to M-SAD model of optimal portfolio selection under the returned rate is known. The formula expressed the change of absolute deviation percentage when standard deviation $v$ increased by $1 \%$.

$$
\mathrm{E}=\frac{\Delta w / w}{\Delta v / v}=\frac{\left(w_{m}-w_{s}\right) /\left(w_{m}+w_{s}\right)}{\left(v_{m}-v_{s}\right) /\left(v_{m}+v_{s}\right)}
$$

\section{Empirical research}

Example: In order to illustrate the proposed methods, let us consider the following 20 securities which are choose from Shanghai 50 stocks. The table below is the optimal solution by the model of $\mathrm{M}-\mathrm{V} . r_{e}$ is expected return rate, $v_{\mathrm{m}}$ is portfolio variance, $\omega_{\mathrm{m}}$ is semi-variance absolute deviation, $v_{\mathrm{m}}$ is Standard deviation

Table1 Optimal investment strategy of M-V

\begin{tabular}{llllllllll|l|l}
\hline \multicolumn{7}{c|}{ the optimal solution } & \multicolumn{2}{l|}{$V_{e}$} & \multirow{2}{*}{} \\
\hline$s_{1}$ & $s_{2}$ & $s_{3}$ & $s_{4}$ & $s_{5}$ & $s_{6}$ & $s_{7}$ & $s_{8}$ & $s_{9}$ & $s_{10}$ & & \\
\hline 0.000 & 0.000 & 0.000 & 0.000 & 0.000 & 0.000 & 0.000 & 0.000 & 0.000 & 0.000 & 1.0 & 0.023 \\
0 & 0 & 0 & 0 & 0 & 0 & 0 & 0 & 0 & 0 & 4 & 0 \\
\hline 0.000 & 0.000 & 0.000 & 0.000 & 0.000 & 0.000 & 0.000 & 0.000 & 0.000 & 0.000 & 1.0 & 0.003 \\
0 & 0 & 0 & 0 & 0 & 0 & 0 & 0 & 0 & 0 & 6 & 4 \\
\hline 0.000 & 0.000 & 0.000 & 0.000 & 0.000 & 0.000 & 0.000 & 0.000 & 0.000 & 0.000 & 1.0 & 0.029 \\
0 & 0 & 0 & 0 & 0 & 0 & 0 & 0 & 0 & 0 & 8 & 6 \\
\hline 0.000 & 0.000 & 0.000 & 0.000 & 0.000 & 0.000 & 0.000 & 0.000 & 0.000 & 0.000 & 1.1 & 0.023 \\
0 & 0 & 0 & 0 & 0 & 0 & 0 & 0 & 0 & 0 & 0 & 0 \\
\hline
\end{tabular}




\begin{tabular}{llllllllll|l|l}
\hline 0.000 & 0.000 & 0.000 & 0.000 & 0.000 & 0.000 & 0.000 & 0.000 & 0.000 & 0.000 & 1.1 & 0.036 \\
0 & 0 & 0 & 0 & 0 & 0 & 0 & 0 & 0 & 0 & 2 & 9 \\
\hline 0.000 & 0.000 & 0.000 & 0.000 & 0.000 & 0.000 & 0.000 & 0.000 & 0.000 & 0.000 & 1.1 & 0.058 \\
0 & 0 & 0 & 0 & 0 & 0 & 0 & 0 & 0 & 0 & 4 & 1 \\
\hline 0.000 & 0.000 & 0.000 & 0.000 & 0.000 & 0.000 & 0.000 & 0.000 & 0.000 & 0.000 & 1.1 & 0.079 \\
0 & 0 & 0 & 0 & 0 & 0 & 0 & 0 & 0 & 0 & 6 & 9 \\
\hline 0.000 & 0.000 & 0.000 & 0.000 & 0.000 & 0.000 & 0.000 & 0.000 & 0.000 & 0.000 & 1.1 & 0.100 \\
0 & 0 & 0 & 0 & 0 & 0 & 0 & 0 & 0 & 0 & 8 & 6 \\
\hline 0.000 & 0.000 & 0.000 & 0.000 & 0.000 & 0.000 & 0.000 & 0.000 & 0.000 & 0.000 & 1.2 & 0.121 \\
0 & 0 & 0 & 0 & 0 & 0 & 0 & 0 & 0 & 0 & 0 & 9 \\
\hline
\end{tabular}

\begin{tabular}{|c|c|c|c|c|c|c|c|c|c|c|c|}
\hline \multicolumn{10}{|c|}{ the optimal solution } & \multirow[t]{2}{*}{$r_{e}$} & \multirow[t]{2}{*}{$V_{m}$} \\
\hline$s_{11}$ & $s_{12}$ & $s_{13}$ & $s_{14}$ & $s_{15}$ & $s_{16}$ & $s_{17}$ & $s_{18}$ & $s_{19}$ & $s_{20}$ & & \\
\hline 0.000 & 0.000 & 0.000 & 0.000 & 0.000 & 0.000 & 0.000 & 0.000 & 0.000 & 1.000 & 1.0 & 0.023 \\
\hline 0 & 0 & 0 & 0 & 0 & 0 & 0 & 0 & 0 & 0 & 4 & 0 \\
\hline 0.000 & 0.000 & 0.000 & 0.871 & 0.000 & 0.000 & 0.000 & 0.000 & 0.000 & 0.128 & 1.0 & 0.034 \\
\hline 0 & 0 & 0 & 7 & 0 & 0 & 0 & 0 & 0 & 3 & 6 & 5 \\
\hline 0.000 & 0.000 & 0.000 & 0.500 & 0.000 & 0.000 & 0.000 & 0.000 & 0.000 & 0.500 & 1.0 & 0.029 \\
\hline 0 & 0 & 0 & 0 & 0 & 0 & 0 & 0 & 0 & 0 & 8 & 6 \\
\hline 0.000 & 0.000 & 0.000 & 0.128 & 0.000 & 0.000 & 0.000 & 0.000 & 0.000 & 0.871 & 1.1 & 0.024 \\
\hline 0 & 0 & 0 & 3 & 0 & 0 & 0 & 0 & 0 & 7 & 0 & 7 \\
\hline 0.000 & 0.000 & 0.127 & 0.000 & 0.000 & 0.000 & 0.000 & 0.000 & 0.000 & 0.872 & 1.1 & 0.036 \\
\hline 0 & 0 & 3 & 0 & 0 & 0 & 0 & 0 & 0 & 7 & 2 & 9 \\
\hline 0.000 & 0.000 & 0.321 & 0.000 & 0.000 & 0.000 & 0.000 & 0.000 & 0.000 & 0.678 & 1.1 & 0.058 \\
\hline 0 & 0 & 7 & 0 & 0 & 0 & 0 & 0 & 0 & 3 & 4 & 1 \\
\hline 0.000 & 0.000 & 0.516 & 0.000 & 0.000 & 0.000 & 0.000 & 0.000 & 0.000 & 0.484 & 1.1 & 0.079 \\
\hline 0 & 0 & 0 & 0 & 0 & 0 & 0 & 0 & 0 & 0 & 6 & 9 \\
\hline 0.000 & 0.000 & 0.710 & 0.000 & 0.000 & 0.000 & 0.000 & 0.000 & 0.000 & 0.289 & 1.1 & 0.100 \\
\hline 0 & 0 & 4 & 0 & 0 & 0 & 0 & 0 & 0 & 6 & 8 & 6 \\
\hline 0.000 & 0.000 & 0.904 & 0.000 & 0.000 & 0.000 & 0.000 & 0.000 & 0.000 & 0.095 & 1.2 & 0.121 \\
\hline 0 & 0 & 8 & 0 & 0 & 0 & 0 & 0 & 0 & 2 & 0 & 9 \\
\hline
\end{tabular}

Table1 shows the expected return of a portfolio, Standard deviation and semi-variance absolute deviation of M-V.Using the formula (3.2) to work out the risk elasticity of the model of M-SAD and $\mathrm{M}-\mathrm{V}$, as shown in the following illustration.

Chart1 absolute value of Risk elasticity

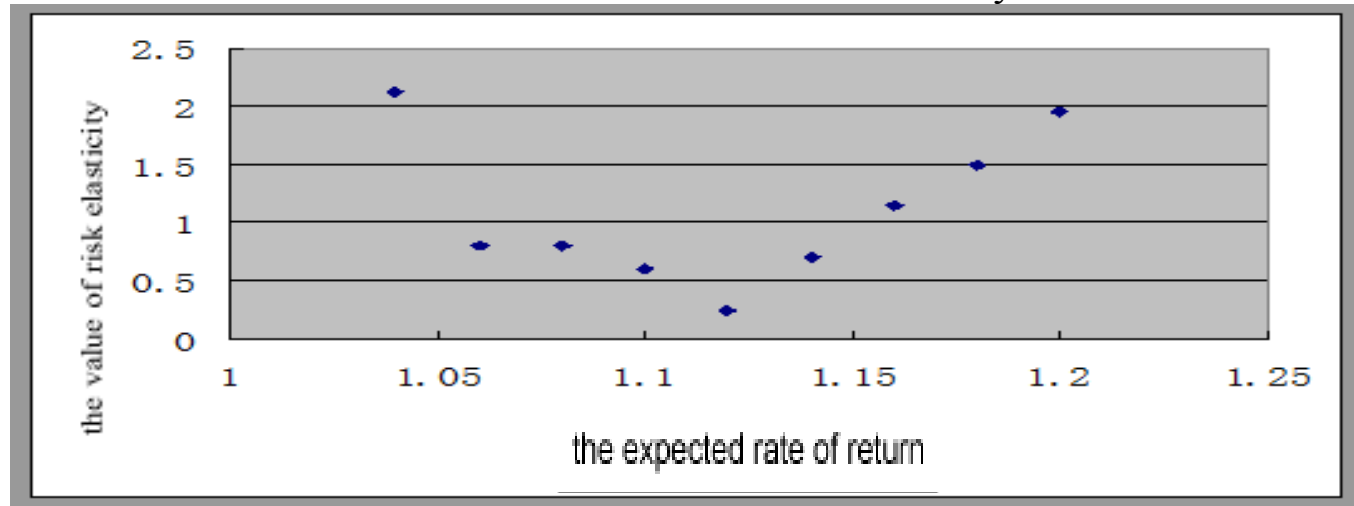

From the above diagram, absolute value of elasticity appearing are less than 1, and it is not the same with the test model validity conditions. When $\mathrm{Xu}$ and Chen proposed risk elasticity, the model of M-V and M-SAD had allowed short sale. However, the paper discussed optimal asset allocation in no short-selling condition, which is $\mathrm{x}_{\mathrm{i}} \geq 0$.In no short-selling condition, the Validity of model of $\mathrm{M}-\mathrm{V}$ and $\mathrm{M}-\mathrm{SAD}$ is reasonable by risk elasticity. Otherwise, risk elasticity will lose efficacy. 
The chart below shows semi-variance absolute value of M-V model compared with M-SAD model.

Chart2 the comparison between M-V and M-SAD

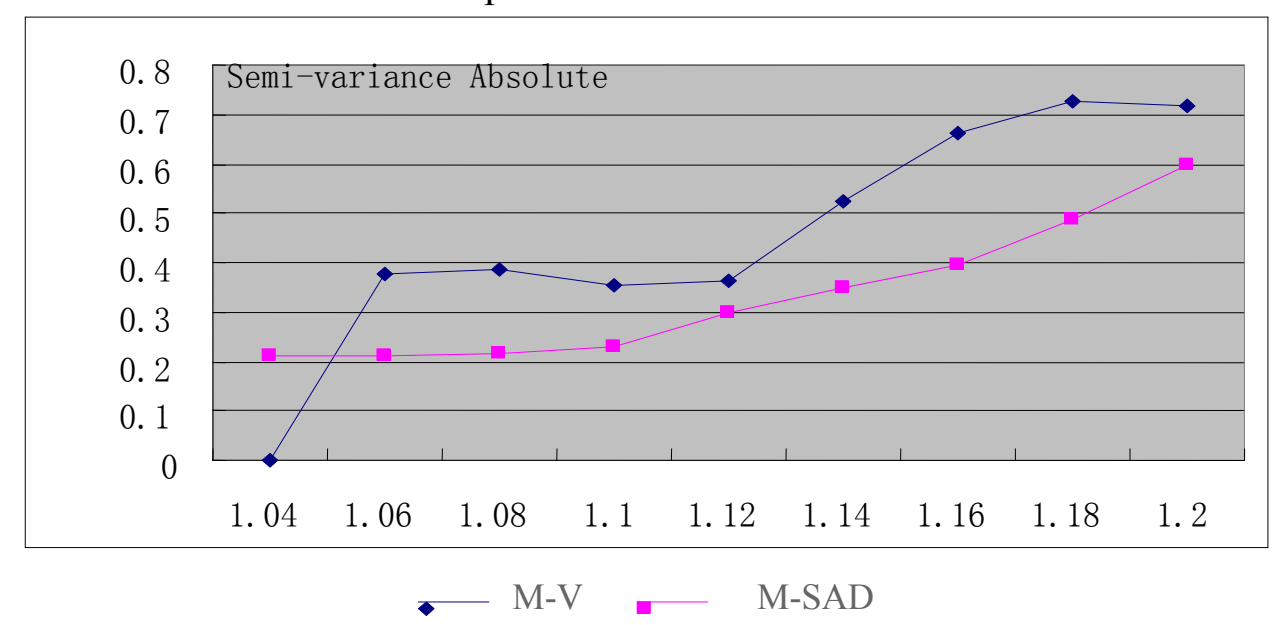

It can be seen above semi-variance absolute values of $\mathrm{M}-\mathrm{V}$ are larger than $\mathrm{M}-\mathrm{SAD}$, so the risk of portfolio used by M-SAD model is greater than M-V model. When the risk measurement tool of risk is semi-variance absolute deviation, the risk measured by the M-SAD model is superior that of $\mathrm{M}-\mathrm{V}$ model.

\section{Conclusion and Expectation}

The M-SAD model approach has been extended in this paper to single-period portfolio selection. In the paper, we described the basic theory, and built a M-SAD model under the condition that short selling is forbidden. We, at last, fund 20 stocks that outperformed in the market to do the empirical research. Empirical research can be seen above semi-variance absolute values of $\mathrm{M}-\mathrm{V}$ are larger than M-SAD, so the risk of portfolio used by M-SAD model is greater than M-V model. The Validity of model of M-V and M-SAD is reasonable by risk elasticity in no short-selling condition. Accordingly, the development of China securities market is not mature, with financial industry of China expand opening to the outside world and mechanism system increasingly perfect, the advanced financial risk measurement methods will play an important role in the financial development of China.

\section{Acknowledgements}

This work was supported by NSFC, No. 71271161; SSFMEC, No.09YJC630182.

\section{References}

[1] Zhang Peng, Zhang Zhong-zhen, Yue Chao-yuan. Optimization of the Mean Semi-absolute Deviation Portfol io Selection Model with the Restricted Short Selling Based on the Pivoting Algorithm [J]. Chinese Journal of Management Science, 2006, 1: 7-10. (in Chinese)

[2] Inuiguchi, M., Ramik, J.: Possibilistic Linear Programming: A Brief Review of Fuzzy Mathematical Programming and a Comparison with Stochastic Program-ming in Portfolio Selection Problem. Fuzzy Sets and Systems 111 (2000) 3-28.

[3]Markowitz H. . Portfolio selection[J]. The Journal of Finance, 1952,7: 77 91

[4]Kaplan, P. D., \& Alldredge, R. H. (1997). Semivariance in risk-based index construction: Quantidex global indexes. The Journal of Investing, 6, 82-87.

[4]Peng Zhang. The Research On the Multiperiod M-V Portfolio Selection Optimization by Discrete Approximate Iteration. Practice and cognition of mathematics，2009，39（8）,44 52 
[5]Shi nong Wu, Study on Chinese stock market risk [M]. China People's University Press, 2003,33 50

[6]Alexander G J, Sharpe W F. Fundamentals of Investments[M]. New Jersey: Prentice-Hall, 1998

[7]Konno, H. , Yamazaki H. Mean-absolute Deviation Portfolio Optimization model and its applications to Tokyo stock market[J]. Management Science, 1991，37(5): 519 531

[8] Huang, X. (2008). Portfolio selection with a new definition of risk. European Journal of Operational Research, 186, 351-357.

[9]Dasheng Yuan, Dahong Shao, Shilian Yu. LINGO and EXCEL application in mathematical modeling [M]. Science Press, 2007, 1-50, 9-101 